\title{
LA DINÁMICA DEL EROS EN EL COLLAR DE LA PALOMA DE IBN HAZM DE CÓRDOBA
}

\section{THE DYNAMICS OF EROS IN THE RING OF THE DOVE BY IBN HAZM}

\author{
Rafael Las Heras ${ }^{1}$ \\ Universidad de Málaga (España)
}

\begin{abstract}
Resumen: El objeto de esta investigación es tratar del nacimiento, crecimiento y plenitud de las relaciones amorosas en la obra de Ibn Hazm de Córdoba. La hipótesis

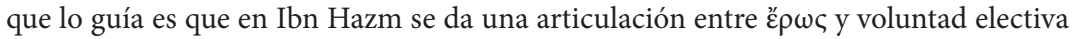
sin la cual el dinamismo amoroso no llega a su fin. Las investigaciones hasta la fecha subrayan aspectos algunos aspectos del platonismo de Ibn Hazm como el poder elevante del amor y su fuerza unitiva, pero no suelen caracterizar metafísicamente el eros y desatienden el momento reflexivo y unitivo, que sin embargo es necesario para Ibn Hazm dada la intención ética que preside El collar de la paloma..
\end{abstract}

Palabras clave: IBN HAZM - AMOR - NEOPLATONISMO - VOLUNTAD ELECTIVA - EROS.

\begin{abstract}
The main object of this dissertation is to see the beginning, development and plenitude of love in the work of Ibn Hazm. The hypothesis which guides Ibn Hazm is that there is an articulation between eros and the elective will. Without this, the dynamic of love does not reach its end. The investigations up until the date established, remarks some aspects of the Platonism of Ibn Hazm as the uprising power of Love and its unitive strength. However, they lack metaphysical description of eros. Consequently, they disregard the reflective and unifying moment of love. Nevertheless, this moment is extremely important to Ibn Hazm given his ethical intention which prevails in The Ring of the Dove.
\end{abstract}

Key words: IBN HAZM - LOVE - NEOPLATONISM - REFLECTIVE WILL - EROS

[1] (rafalasheras@gmail.com) es graduado en filosofía por la Universidad de Málaga (España) 


\section{Objeto de esta investigación e hipótesis de partida}

\subsection{El mayor de los tratados sobre el amor en el islam.}

El objetivo de este trabajo es tratar del nacimiento, crecimiento y plenitud de las relaciones amorosas ${ }^{2}$ en la obra de un gran filósofo, poeta, jurista, historiador y teólogo medieval español: Ibn Hazm Al-Zahiri o de Córdoba (994-1064 d.C. o 384-456H).

Según Ortega, su obra es la «más ilustre sobre el tema del amor en la civilización musulmana». ${ }^{3}$ Los méritos de la poesía y la filosofía contenidas en El collar de la paloma ${ }^{4}$ son de sobra conocidos desde las reivindicaciones que hicieron de esta obra tanto José Ortega y Gasset ${ }^{5}$ como los arabistas Emilio García Gómez ${ }^{6}$, y Miguel Asín Palacios ${ }^{7}$. El primero de ellos llegará a decir que «este libro es el más ilustre sobre el tema del amor en la civilización musulmana». ${ }^{8}$ Chejne llega a afirmar que es la obra más excelente, no sólo de Ibn Hazm, sino de toda la literatura árabe. ${ }^{9}$ Quizás la valoración de El collar de la paloma por Chejne sea un poco exagerada. Pero es muy indicativa de la calidad y el reconocimiento que ha tenido éste, por lo que no parece aventurado estudiar el tratamiento de la dinámica amorosa en este libro, que puede abrir nuestra comprensión filosófica a la perspectiva cultural oriental.

Se trata de un autor sumamente importante, para la filosofía y «la ciencia musulmana de todas las épocas» ${ }^{10}$ y del que hay aún mucho que investigar. Paulina López Pita dirá de él que «revitaliza el pensamiento islámico de Occidente». ${ }^{11}$ Tan importante es a los ojos de los historiadores de la filosofía medieval, que también se ha dicho, que «la fama de su nom-

[2] Estas relaciones incluyen para Ibn Hazm también las de amistad, a las que se refiere reiteradamente en El collar de la Paloma.

[3] J. Ortega y Gasset, «Prólogo» en Ibn Hazm de Córdoba, El collar de la paloma, Alianza Editorial, Madrid, 2012 (3a edición), p. 13.

[4] Ṭawq al-Ḥamāmah fī 1-ulfa wa-1-ullāf.

[5] Ortega y Gasset, Op. cit.

[6] García Gómez, E. «Introducción» en Ibn Hazm de Córdoba, El collar de la paloma, Alianza Editorial, Madrid, 2012 (3ª edición).

[7] Asín Palacios, M., Abenházam de Córdoba y su Historia crítica de las ideas religiosas,

[8] Ortega y Gasset, J., «Prólogo» en Ibn Hazm de Córdoba, El collar de la paloma, Alianza Editorial, Madrid, 2012 (3ª edición), p. 13.

[9] Cfr.: Chejne, A. G., Ibn Hazm, Kazi Publications, Chicago, 1982, pp. 132-138.

[10] García Gómez, E. «Introducción» en Ibn Hazm de Córdoba, El collar de la paloma, p. 51.

[11] López Pita, P., «El collar de la paloma. Tratado sobre el amor y los amantes» en Espacio, Tiempo y Forma, Serire III, Historia Medieval, t. 12, 1999, p. 71. 
bre hubiera debido brillar desde un principio a par, si no más alta, que la de los nombres de Averroes o Maimónides». ${ }^{12}$ Sus obras son numerosas. No hay un censo actual definitivo, y se estima que constan de «80.000 folios escritos de su mano, formando 400 volúmenes». ${ }^{13}$

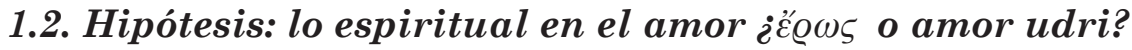

El título de nuestro libro, el collar de la paloma alude remotamente al Fedro y al Banquete platónicos. Para Platón el alma, en su ascenso dialéctico a las ideas y al bien, le van naciendo alas a medida que logra engendrar en la belleza percibida en su alma. La paloma es ese símbolo del alma caída en un cuerpo. El símbolo de la paloma es usado profusamente en la poesía islámica de raigambre neoplatónica. «Según Ibn Dāwūd de Isfahan, a quien Ibn Hazm cita en su obra, aquello que entre los hombres se llama "amor», entre los dioses iniciados se llama «Pteros» o "paloma revoloteante»; un antiguo símbolo del dios alado que impulsa al alma a buscar lo que es divino en ella misma (Platón, Fedro, 247-253)». ${ }^{14}$ Así, parece que Ibn Hazm, al poner este título a su obra, está reivindicando el sentido del ع́ow,$^{15}$ es decir de lo que los filósofos medievales llamarán voluntas ut natura como fuerza del espíritu humano.

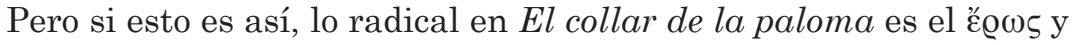
no meramente el amor cortés, o amor udri, como tradicionalmente se viene diciendo. Es un tópico que la concepción del amor contenida en El collar de la paloma parece guardar numerosas afinidades con la que tiene su coetáneo Ibn Zaydun con su concepción del amor cortés, o amor espiritual. Efectivamente el amor del que habla Ibn Hazm es fundamentalmente puro, y por lo tanto condena la infidelidad, el adulterio, las relaciones ilícitas. Parecería entonces que Ibn Hazm se afiliaría a la corriente sufí del amor udrí (al-'Udhri). «El amor udri — practicado por la tribu de los Banu Udra o «Hijos de la Virginidad» de Yemen - era un ideal amatorio que se daba entre las gentes que se abstenían de los contactos físicos y de las relaciones sexuales con el fin de lograr la unión intelectual entre dos amantes». ${ }^{16}$

[12] García Gómez, E. «Introducción» en Ibn Hazm de Córdoba, El collar de la paloma,.. p. 64.

[13] Ibid., p. 51.

[14] Mujica Pinilla, El collar de la paloma del alma. Amor sagrado y amor profano en la enseñanza de Ibn Hazm y de Ibn Arabi, Hiperión, Madrid, 1990, p. 41.

[15] Cfr.: Izharul Haq, M., «Comparative Study of Love and Eros among Plato, Ibn Hazm and Modern Philosophers», en Al-Hikmat, vol. 22 (2002), pp. 33-42. Para este autor, Ibn Hazm realiza una síntesis entre platonismo e Islam, posibilitada por la experiencia personal de Ibn Hazm

[16] Mújica Pinilla, El collar de la paloma del alma....,op. cit., p. 55. 
La mayor parte de la bibliografía sobre El collar de la paloma está realizada desde el plano metodológico de la filología. ${ }^{17}$ Y para la Historia de la literatura española es muy importante rastrear las fuentes de un movimiento literario tan importante como el amor cortés, etc., que tan influyente sería en nuestras letras. ${ }^{18} \mathrm{Si}$ el plano de consideración no es el filológico, sino el filosófico, entonces lo que aparece es la relevancia del ع́ows platónico. Aspecto éste no suficientemente resaltado por la bibliografía, y cuyos implícitos son el objeto de este trabajo.

La característica filosófica más sobresaliente de Ibn Hazm es su agudeza psicológica. Quizá en la historia de la filosofía alcance el parangón de Nietzsche o Kierkegaard, y en el de la literatura, el parangón de Dostoievski. Esta psicología no es ajena a una intención moral. Registra con suma sensibilidad cualquier movimiento corporal o psicológico que tenga sentido. Pero está presidida por una intención «de salvar y promover la cultura humana (esto es, la cultura árabe de su tiempo)». ${ }^{19}$ Esto es lo que explica el punto de vista con que Ibn Hazm se acerca a las cuestiones amorosas. Es un punto de vista que no es ajeno a la ética, ni a la condena del vicio.

Y esto explica que en El collar de la paloma no sólo esté presente el amor cortés, sino también otras formas de amar, como la pasional, la amistad, la espiritual. Pero en todas ellas, la intención que preside nuestro libro es ética. Cuando habla de la amistad, por ejemplo, entonces sostiene que sólo en una atmósfera de relaciones sinceras, de franqueza, de interés y comprensión es posible la búsqueda de la verdad.

\section{La filosofía arábigo-andaluza de Ibn Hazm: punto de en- cuentro entre islam, cristianismo y filosofía grecorromana de la vida.}

El collar de la paloma fue escrito en Jativa alrededor del año 1022. Córdoba vivía el momento más trágico de su historia, pues había perdido —hacía muy poco—, su influencia política como Califato. Córdoba había sido destruida por tribus bereberes. El Califato que le dio grandeza, quedó

[17] «Incluso cuando un pensador de los conocimientos y de la extraordinaria agudeza de Ortega y Gasset se enfrenta con la obra de Ibn Hazm El collar de la Paloma, guidado exclusivamente por la estimación unilateral y preferentemente literaria de Ibn Hazm, desvaloriza el resto de su pensamiento y lo considera mera repetición escolástica». Cruz Hernández, M., «El neoplatonismo de Ibn Hazm de Córdoba» en Miscelánea de estudios árabes y hebraicos. Sección Árabe-Islam, Vol. 11, 1962, p. 121.

[18] Sobre la influencia de Ibn Hazm en la tradición literaria del amor cortés: cfr.: Nathan Hickman, D., Ibn Hazm: an Islamic Source of Courtly Love, Tesis doctoral: University of Tennessee, Knoxville, 2014.

[19] Arnaldez, R., «Ibn Hazm» en Encyclopaedia of Islam, Brill, p. 791. 
disuelto. Y reinaba por doquier la anarquía de los reinos de Taifas. Ibn Hazm es, por lo tanto, protagonista y testigo privilegiado de uno de los más trágicos momentos de la cultura musulmana. Este derrumbe de la época califal tuvo consecuencias trágicas para él. Su padre fue asesinado, su familia quedó arruinada, y tienen que emprender el camino del exilio, en reiteradas ocasiones. Será bien lejos de Córdoba, en Játiva, donde escribirá El collar de la paloma, con sólo veinte y ocho años de edad, en el año 1022 de nuestra era, 412 de la Hégira.

Nuestro libro evoca aquellos momentos de esplendor de la capital del Califato de Occidente. Según los arabistas es «casi la única evocación eficaz que poseemos sobre lo que la civilización cordobesa en los últimos días del Califato. ${ }^{20}$ Desde joven, Ibn Hazm formaba parte de la escuela literarita de los jóvenes estetas de Córdoba y era discípulo de Abū 'Āmir ibn Šuhayd (992-1035). De él bebe su admiración por el esplendor califal de Córdoba, y su desprecio por lo vulgar, lo mozárabe y lo muladí. Es por eso, que El collar de la paloma tiene una identidad muy propia. No es meramente una obra de un filósofo árabe, sino de un filósofo arábigo-andaluz. Y esto es un aspecto muy destacado tanto por Ortega y Gassett como por García Gómez. La Córdoba califal es vista pues, como el puente de Oriente a Occidente, y no como una obra completamente oriental. Esta tesis de Ortega es sumamente importante, porque señala en momento en el que la extensión de la filosofía griega hacia Persia, Siria, Bagdad y Al Andalus engarza con Occidente. ${ }^{21}$ Esta confluencia de Oriente y Occidente se aprecia ya en el origen étnico de Ibn Hazm, pues era muladí.

Pero en la filosofía arábigo-andaluza hay algo más que la confluencia entre Oriente y Occidente. Algo que está aún por estudiar, y de lo que ahora mismo estamos a mucha distancia. Como Ortega y Gasset dice «nuestra sociedad ha convivido durante siglos con esa sociedad andaluza, piel contra piel, en roce continuo de beso y lanzada, de toma y daca, de influjo y recepción. Y una de las grandes vergüenzas que desdoran los estudios históricos es que, a estas alturas, ni de lejos se haya logrado establecer la figura de la relación entre ambas sociedades». ${ }^{22}$ En las páginas de El collar de la paloma afloran las relaciones sociales de las que habla Ortega. Este tema intercultural, quizá hoy sea más necesario que nunca estudiarlo. Las migraciones, los desplazamientos masivos de refugiados de

[20] Ibid., p. 69

[21] Como es bien sabido, las otras líneas de recepción del platonismo en la filosofía medieval son la bizantina, la judaica y la arábiga. De la arábiga pasará a la latina. Y aquí radica la enorme importancia de Ibn Hazm.

[22] Ortega y Gasset, «Prólogo» op. cit., p. 14. 
guerra, etcétera, acentúan la necesidad de releer las páginas de Ibn-Hazm sobre las relaciones intersubjetivas entre culturas.

Pues bien, en la filosofía arábigo-andaluza hay tres factores muy importantes que se articulan: la cultura y el saber islámico, la cultura y el saber cristiano, y «un área común impregnada por la cultura grecorromana». ${ }^{23} \mathrm{He}$ aquí la novedad histórica del contexto de El collar de la paloma. Muchos siglos más tarde, el relevo de la filosofía lo tomaría la filosofía alemana. Pero, y ésta es la tesis de Ortega, la filosofía alemana no logra dialogar con la filosofía musulmana. Este diálogo era más propicio al cristianismo católico del Sur y a la filosofía grecorromana de la vida.

\section{El método de El collar de la paloma: vida y reflexión sobre la vida en Ibn Hazm de Córdoba}

\subsection{Ibn Hazm y la escuela Z̄āhirī}

Ibn Hazm fue sumamente polémico en su propio tiempo. Sus obras fueron perseguidas por los representantes políticos y religiosos de su cultura. Y es que interesaban no sólo a los doctos e instruidos, sino que sus enseñanzas levantaban pasiones en el pueblo llano del Al-Andalus del siglo XI. A este carácter controvertido contribuyó, sin duda, su inclinación, llena de ardor y pasión, por la polémica desde su juventud. ${ }^{24}$ En sus reflexiones jurídicas se mostrará como un literalista, un Zāhirī, es decir como un defensor del sentido literal, manifiesto (Zāhir) de las expresiones coránicas y del hadiz.

Esta filiación jurídica — Zāhirī— es muy importante en El collar de la paloma, puesto que a ella se debe otra de las características más sobresalientes de nuestro libro: su amor y respeto al lenguaje. "Su estilo es al mismo tiempo límpido, ágil y vigoroso. Desde este punto de vista, sus obras se conforman completamente con el ideal occidental». ${ }^{25}$

[23] Ibid., p. 15. El conocimiento de la filosofía griega por Ibn Hazm es indirecto. Como concluye Librán Moreno: «Ibn Hazm pudo tener cierto grado de contacto indirecto con el sistema de motivos amatorios que aparece en la poesía elegíaca y epigramática y en la novela grecolatinas. Dicho contacto pudo producirse de forma mediata gracias a autores árabes anteriores y fundamentalmente a través de tres vehículos: (a) antologías, doxografías y comentarios de filósofos griegos traducidos al árabe; (b) textos médicos griegos; (c) traducciones, adaptaciones y refundiciones de novelas griegas.» Miryam Librán Moreno «Tópicos amatorios de origen grecolatino en Ibn Hazm de Córdoba» en Caurensia. Vol. IV, 2009. p. 189

[24] Cfr.: Ortega y Gasset, «Prólogo», op. cit., p. 71.

[25] Arnaldez, R., «Ibn Hazm», op. cit., p. 792. 
Además, esto es importante, porque señala otra característica muy extraña y quizá la más sobresaliente del Collar de la paloma, y es su continua apelación a las situaciones vitales a los casos reales, conocidos en primera persona, o por fuentes muy cercanas. El tratado no recurre a ninguna especulación, sino que es una reflexión sobre la vida, desde la vida y para aclarar la vida. Por eso recurre a ejemplos reales, a reflexiones íntimas, a la persuasión de la poesía. Observo aquí de nuevo el poder de penetración psicológica de Ibn Hazm, que está ligado a la observación de casos reales, de los detalles aparentemente más insignificantes (pero que se muestran tras su observación, los más reveladores), y a la propia introspección. También hay que reseñar su afán por contrastar las informaciones, que sean veraces, y que ante todo, la información transmitida sea precisa.

Cuando narra vivencias, Ibn Hazm logra penetrar en el sentido oculto de palabras, gestos, movimientos corporales. Ahí reside su genio como psicólogo, que no se queda en el sentido aparente, sino que desvela las profundidades anímicas y espirituales, las intenciones ocultas, e incluso inconfesables. En este sentido «es un análisis despiadado de los motivos, intenciones y sentidos secretos que revelan las reticencias o disimulos ocultos bajo la capa de la expresión lingüística». ${ }^{26}$ Este análisis es simultáneamente psicológico, moral y teológico. Y en él se revela un genio no sólo de la literatura, sino de la psicología filosófica.

Se trata pues de un libro sumamente personal. «Que el libro es personal no lo dudará ni un instante quien lo abra». ${ }^{27}$ Más aún, nuestra «obra es, en cierto modo, su autobiografía y aun la autobiografía del grupo literario a que el autor pertenecía». ${ }^{28}$ Una de las características más sobresalientes de nuestro libro es la conjunción de conciencia y sensibilidad que muestra Ibn Hazm. Se trata de una personalidad muy sensible, que registra conscientemente hasta los más nimios movimientos del alma y del cuerpo de los amantes. Como mostró Asín Palacios esta conciencia sensitiva se formó en el harén donde pasó su infancia. Este hecho es congruente con su afiliación a la escuela zahirista, con su desdén por toda deducción y del razonamiento analógico.

[26] Ibid., p. 793.

[27] Ortega y Gasset, «Prólogo», op. cit., p. 68

[28] Ibid., p. 71. El propio Ibn Hazm se educó en un harén, por lo que conoció de primera mano las pasiones amorosas en hombres y mujeres. Pasiones como la atracción, los celos, el sufrimiento por la muerte de la amada, el dolor por las atenciones no correspondidas. Así lo narra a propósito del amor tan intenso que despertó en él, durante su estancia en el harén, la joven esclava Nu’m y el dolor que le provocó su prematura muerte. 


\subsection{El género literario de El collar de la paloma: risāla y dīwān}

Del Collar de la paloma sólo se ha conservado un códice ${ }^{29}$ que, según Emilio García Gómez, está «afeado por los descuidos e incomprensiones del copista». ${ }^{30} \mathrm{El}$ género literario de nuestro libro es la risāla ${ }^{31}$, es decir, un tratado. Este tratado está escrito en forma epistolar, en él introduce en diferentes sitios algunas poesías propias (dīwān) También Avicena escribirá una Risāla fi'l-Ishq, es decir un Tratado sobre el amor. Aunque no se trata de la Maqama, sin embargo, guarda semejanzas con ella. En efecto, la Maqama es un género que hoy podríamos considerar cercano a la filosofía, pero que resulta difícil de encontrar. Es, por una parte, literario, puesto que en las narraciones maqámicas tratan de cómo se gana la vida el personaje central. Pero éste lo hace por su inteligencia y sus palabras. En esto se asemeja al diálogo platónico. La risāla de Ibn Hazm tiene la cercanía del diálogo epistolar, pero no expone los debates y las conclusiones de ningún personaje, sino que la propia experiencia vivida, junto con la que conoce cercanamente se trenzan en la exposición de un tratado científico.

El Collar de la paloma no es un libro que surja de la nada. Está situado en una rica tradición árabe de literatura sobre el amor. El género poético del Nasīb es muy antiguo y se remonta al siglo VI. Incluso en la arabia preislámica se cultivaba la qașīda que en muchos casos tiene temática amorosa. Otro de los géneros poéticos es el Gazal, el género que en la Andalucía actual ha quedado en el amor al piropeo. Pero El collar de la paloma se distancia, ya desde su mismo prólogo, de estos géneros literarios, a los que considera meros juegos o liviandades. Su interés es propiamente filosófico, y no la lírica o el jugueteo o devaneo poético ligado al amor.

\subsection{El prólogo y la cuestión de la liviandad del amor.}

Desde este presupuesto metodológico hay que entender el prólogo a nuestro libro. El collar de la paloma se abre con una plegaria que implora al Dios clemente y misericordioso. Tras ella aparece el prólogo en el que declara el objeto de la obra:

[29] El único códice conservado se encuentra en la Biblioteca de la Universidad de Leiden (col. Levinus Warner, 461 Or. 927).

[30] García Gómez, E. «Introducción»., en op. cit., p. 66.

[31] Una risāla es una composición poética tradicional del mundo arábigo-andaluz de la Baja Edad Media. Los temas suelen ser amorosos, y un poco pícaros. Su gran cultivador fue Ibn Al-Murabial-Azdi de Vélez Málaga. 
«Me has pedido, Dios te honre, que componga para ti una risāla, en la que pinte el amor, sus aspectos, causas y accidentes y cuanto en él o por él acaece; y que esto lo haga con veracidad, sin desmesura ni minucia, sino declarando lo que se me ocurra tocante a cómo es y a cómo se presenta, hasta donde llegue mi memoria y mi capacidad de recordar». ${ }^{32}$

El prólogo también acaba con otra oración, en la que pide a Dios perdón y ayuda para llevar a cabo la obra que su corresponsal le ha pedido. La temática de El collar de la paloma aparece entonces clara. El amor y sus formas, sus causas y cuanto en él o por él acaece: esto es el origen del amor y su dinámica. Justo el objetivo de nuestro trabajo. Las plegarias iniciales y finales del prólogo no son fruto de la mera costumbre de un devoto musulmán. Ibn Hazm es un filósofo medieval. Y esto significa que, a diferencia de nosotros, no ve una distancia entre su fe y su reflexión filosófica. Como bien señala Arnáldez, para Ibn Hazm «la fe musulmana, en su autenticidad, es la base de la verdadera vida humana; pero debe ser purificada de todo lo que los hombres le han añadido, suprimido o modificado». ${ }^{33}$

Por eso las precauciones del autor a la hora de tratar del amor están relacionadas con el temor de tratar de un asunto que Ibn Hazm califica de «asunto liviano», "niñería», «una cana al aire». Eso es lo que habían hecho sus predecesores poetas, al escribir nasib, casidas o gazales. Es significativo que la palabra (amor pasional, ishq) no aparezca en el Corán, y que tradicionalmente sea visto como una imperfección que se debe superar para llegar a la santidad (kamāl). Recuérdese también que Ibn Hazm es llamado Al-Zāhirī, es decir un literalista, en lo tocante a la jurisprudencia, para el que el sentido literal del Corán y del Hadiz son los decisivos para derivar el Derecho.

Así pues, esta plegaria del prólogo es una toma de distancia con la literatura árabe (islámica o preislámica) dedicada al amor. Él desea tratar el tema filosóficamente: saber su esencia, sus causas, etcétera. No quiere que su lenguaje sea aprovechado para el mero flirteo. No se trata de un mero poetizar. Y por eso, la observación psicológica se combinará con la intención moral, y con las disquisiciones teológicas, por lo que pide ayuda a lo Alto, a fin de no tratar este tema superficial y vanamente.

Más aún, cuando Ibn Hazm comienza a realizar su discurso sobre la esencia del amor, Ibn Hazm argumenta teológicamente que el amor no es algo liviano ni una niñería. Y que para desvelar su esencia hace falta un elevado sentido psicológico:

«El amor, Dios te honre, empieza de burlas y acaba en veras, y con sus sentidos tan sutiles, en razón de su sublimidad, que no pueden ser declarados, ni puede entenderse su esencia sino tras largo

[32] Ibn Hazmn, op. cit., p. 119.

[33] Arnaldez, R., «Ibn Hazm», op. cit., p. 792. 
empeño. No está reprobado por la fe ni vedado en la santa Ley, por cuanto los corazones se hayan en manos de Dios.» ${ }^{34}$

\section{La dinámica amorosa en El collar de la paloma}

Para cumplir nuestro objetivo, parece claro que hemos de comenzar con la cuestión de la génesis del amor. Es decir, comenzaremos tratando de las causas del amor ${ }^{35}$. Seguiremos con los sintomas que nos permiten inducir si alguien está enamorado. Más adelante trataremos de las cuestiones de la espontaneidad amorosa y la elección en el amor.

\subsection{El inicio de la relación amorosa: el enamoramiento como absolutamente gratuito e inmerecido}

Nada más comenzar El collar de la paloma, Ibn Hazm nos hace reparar sobre la cuestión del encenderse de la relación amorosa. Se trata del momento inicial. Nuestro autor utilizará con frecuencia la metáfora del pedernal. ${ }^{36}$ De aquello que puede hacer saltar la chispa amorosa. Pero advierte que ese algo que puede prender el enamoramiento es tan personal y accidental que imposibilita elaborar una ciencia sobre ello. Es por ello que resulta una pregunta sobremanera difícil averiguar la causa del enamoramiento:

«a menudo vemos que hay quien prefiere alguien de inferior belleza con respecto a otros cuya superioridad reconoce, y que, sin embargo, no puede apartar de él, su corazón. Y si dicha causa consistiese en la conformidad de los caracteres, no amaría el hombre a quien no le es propicio ni con él se concierta». ${ }^{37}$

Parece que no hay una causa: no es la belleza, no es la afinidad de caracteres, ni siquiera el trato prolongado, aquello que acabará en una relación amorosa. Pero que no podamos determinar la causa, implica que

[34] Ibn Hazm, El collar de la paloma, op. cit., p. 126.

[35] Para un compedio de la visión islámica del amor: http://www.encyclopedie-humanisme.com/?Ishq El Profeta usa el término «al-'Alaqa»: la admiración de lo amado que lleva al compromiso permanente con él. También «al-Sababa» (Corán, 12:33) que significa inclinación del corazón hacia lo amado. Uno de los nombres de Dios en el Corán es «Widad» (Corán 19:96, 11:90, 85:14). Los demás términos que denotan amor (Ishq, al-Tatayyum, al-Ta’abbud, al-Khulla) generalmente denotan exceso, olvido de sí por complacer a lo amado, ser esclavo por amor, etc. Sobre la introducción del tema del amor en el sufismo, cfr.: Salto Sánchez del Corral, A.-Ma , El magisterio de las mujeres místicas en el discurso biográfico: Teresa de Jesús y Rābia al-Adawiyya, Tesis Doctoral, Universidad de Málaga, 2015, pp. 296-313.

[36] Ibn Hazm, op. cit. pp.: 132, 163 y otras

[37] Ibn Hazm, op. cit., p. 129. 
tan sólo podemos enumerar diferentes casos. En unos se ha producido por este motivo, en otros por aquel. Pero siempre encontramos que no era necesario que se produjese. Entramos en el terreno de lo contingente. Y por lo tanto de aquello sobre lo que no puede haber una ciencia, si es que la ciencia trata de lo universal y necesario. Ni siquiera cabe hablar de una técnica, porque no está garantizado que quien intenta repetir en el futuro las acciones que produjeron su enamoramiento pasado, tenga éxito.

"Yo he visto a muchas gentes de discernimiento nada sospechoso y en quien no era de temer ni falla en su entendimiento, ni trastorno en su buen juicio, ni deficiencia en su mente, que sin embargo, pintaban a sus amados con ciertas cualidades no gustadas de los demás hombres ni ajustadas a la belleza, pero eran para ellos la perfección misma, el colmo de sus deseos y el ápice de sus gustos. Y si luego estas pasiones se desvanecían [...] ya no perdían el aprecio de aquellas partes, ni dejaban de darles preferencia sobre otras que tiene por mejores la naturaleza humana».38

Lo que gusta y enciende el enamoramiento de un ser humano puede ser «cierta cualidad no gustada por los demás». En este caso el enamoramiento es contemplado como algo individual, como una gracia o un don al que responde el amante, que se ha inflamado en amor por dicho don. Esas cualidades no enamorarían a ningún otro hombre, de acuerdo con la cita. Y sin embargo, la pasión por esas cualidades que ha encontrado quien se enamoró de ellas, quizá sea inextinguible en el futuro. Lo que plantea un problema existencial en caso del fracaso de la relación amorosa.

Más aún, Ibn Hazm deduce de lo anterior que esta persona no podrá enamorarse de aquellas personas cuyas particularidades se oponen a aquellas de las que se enamoró antes. El autor nos proporciona numerosos ejemplos:

«Conozco, por ejemplo, a uno prendado de una mujer de cuello algo corto, a quien ya, después, no le gustaba ningún hombre ni mujer que tuviera el cuello esbelto; a otro cuyo amor fue una muchacha más bien baja, y que ya, después, nunca amó a ninguna mujer alta; a otro, en fin, que habiéndose enamorado de una esclava que tenía una boca rasgada y graciosa, ya, en lo sucesivo detestaba toda boca chica, la censuraba y mostraba por ella verdadera aversión. Y no hablo, por cierto, de gentes inciviles o poco devastadas, sino de hombres más avisados y más merecedores de renombre por su agudeza y entendimiento.. ${ }^{39}$

Observemos que lo que provoca en un caso el amor, en otro es lo opuesto: unos se enamoran de los cuellos cortos, otros de los largos, unos de las bajas, los otros de las altas. Es tal la pluralidad de causas, que no podemos encontrar ninguna ley general. Quizá haya una, que quien se enamora de una cualidad, busca de nuevo esa cualidad. Y la busca como espontáneamente, como si hubiera tenido una vivencia radical. Pero esto

[38] Ibid., p. 129.

[39] Ibid., p. 168 
lo consideraremos en el tercer epígrafe de esta investigación, pues se trata de un momento que sólo arraiga en la vida humana, una vez que se ha producido el enamoramiento, asunto del que estoy tratando ahora.

Volvamos al tema de lo contingente en el nacimiento del amor. Si echamos un vistazo al índice de El collar de la paloma, apreciaremos inmediatamente la multiplicidad y heterogeneidad de las causas del enamoramiento. Hay quien se enamora en sueños, ${ }^{40}$ hay quien se enamora por una sola mirada, ${ }^{41}$ otros que se enamorarán después de un largo trato. ${ }^{42} \mathrm{En}$ cualquier caso, lo que para Ibn Hazm está claro es que «por fuerza ha de tener todo amor una causa que le sirva de origen». ${ }^{43}$ Siempre hay un motivo. Pero esta causa puede ser tan extraña, inopinada, tan poco frecuente que el propio filósofo exclame:

«Entre estos motivos hay uno que, de no haberlo visto con mis propios ojos, ni siquiera hablaría de él, por su extrema rareza.» ${ }^{44}$

El caso al que se refiere Ibn Hazm es el de un amigo suyo que se enamoró profundamente al haber soñado con una esclava a la que nunca había visto. "Amas a quien nunca has visto, que ni ha sido creado ni anda por el mundo». ${ }^{45} \mathrm{El}$ análisis que hace Ibn Hazm de este caso es extraordinariamente revelador. Pues apunta a que la causa de este enamoramiento son dinamismos psíquicos inconscientes como los que siglos después analizará Sigmund Freud.

«Es éste, a mi parecer, un caso de sugestión anímica o de pesadilla, que entra dentro del campo de los deseos reprimidos y de las fantasías del pensamiento.» ${ }^{46}$

Ibn Hazm pues, encuentra causas de lo más variado para el enamoramiento. Es un gran psicólogo, y por eso tiende a analizar los casos más extraños, «los más peregrinos de la pasión».47 Tan heterogéneas pueden ser las causas del amor, que en un capítulo individúe una, y en el siguiente capítulo "lo contrario de lo que acabamos de ver». ${ }^{48}$ Se trata pues de experiencias individuales, personales, y no universalizables. En cualquier caso:

[40] cfr.: ibid. pp.: 151-152.

[41] ibid. pp.: 157-160.

[42] ibid. pp.: 161-166.

[43] Ibid., p. 151.

[44] Ibidem.

[45] Ibid. p. 152.

[46] Ibidem.

[47] Ibid., p. 153.

[48] Ibid., 157 
«Si no fuera porque en esta risala mía no me he propuesto declarar los ardides ni contar las mañas de los enamorados, podría citar casos, cuya veracidad me consta, que dejarían perplejos a los más entendidos y llenos de asombro a los más avisados.» ${ }^{49}$

La disparidad, e incluso oposición y contrariedad, de las causas implica que «es un don absolutamente gratuito, algo inmerecido que el sujeto no sabe por qué ni cómo se produce. $\|^{50}$ Este también puede ser un caso no analizado por Ibn Hazm, el que desconoce la causa de su enamoramiento. Nuestro filósofo se siente atraído por estos casos, a los que intenta averiguar la causa.

El enamoramiento no es pues objeto de una elección, o de una acción dirigida a enamorarse, sino que es más como una pasión, algo que nos sucede de forma aparentemente fortuita. Ibn Hazm hablará del que se finge enamorado como si pudiera elegir de quién enamorarse. Pero esto implica que su enamoramiento es falso:

«Si se atreve a suponer que es él quien ha elegido al ser que ama, pues, si el amor hubiera ocupado su entendimiento, anublado su razón y arruinado su albedrío, se hubiera interpuesto ante él, impidiéndole toda elección voluntaria y deliberada». ${ }^{51}$

En resumen, el amor es algo gratuito, un don. Aunque tiene causas, éstas no son universalizables. No podemos hacer una ciencia sobre la génesis del enamoramiento. Una vez estudiado su origen, debemos pasar ahora a estudiar los síntomas de éste. Una vez hecho esto, podremos investigar su fuerza sobre los sujetos que establecen una relación intersubjetiva fundada en el amor.

\subsection{Etiología del dinamismo erótico: las señales del amor}

Ibn Hazm dedica al tema de los síntomas del enamoramiento, algunas de las primeras páginas de El collar de la paloma. De hecho, podríamos decir, que son las primeras propiamente, puesto que el primer capítulo es introductorio, tratando del "plan de la obra». ${ }^{2}$ Por ello, a los síntomas del amor en los individuos, Ibn Hazm le dedicará el segundo capítulo titulado «Sobre las señales del amor».

Lo primero que Ibn Hazm señala es que los amantes tienden a adorarse, y por eso se miran insistentemente. Se trata de miradas llenas de fervor por la persona que aman. Nuestro autor llegará a decir que «la

[49] Ibid., p. 160.

[50] Choza, J. Antropología de la sexualidad, Rialp, Madrid, 1992, p. 84.

[51] Ibn Hazm, op. cit., p. 170.

[52] Ibid., pp. 123-137 
primera de todas [las señales del amor es] la insistencia de la mirada $\rangle^{53}$. Quienes se quieren buscan ardientemente encontrarse y para ello utilizan cualquier excusa. Incluso es tal la adoración y el culto que se rinden el uno al otro, que tienden a obedecer cualquier deseo de la persona que aman. Incluso

«que encuentre bien cuanto diga, aunque sea un absurdo y una cosa insólita; que le dé la razón, aun cuando mienta; que se muestre siempre de acuerdo con él, aun cuando yerre; que atestigüe en su favor, aun cuando obre con injusticia.. ${ }^{54}$

Es tal el apego que entre sí tienen los amantes, que se olvidan de su propia vida, salen de sí, como en éxtasis. Viven en el otro y no el cuidado de sí. Jacinto Choza, a propósito de esta señal del amor comenta que «los amantes se adoran, se idolatran, se entregan completamente el uno al otro. Y el universo religioso encuentra ahí su significado y justificación más inmediata. ${ }^{55}$ Quizá esto se pueda ver particularmente en un abanico muy amplio de fenómenos que van desde la pérdida del apetito hasta la ansiedad de los enamorados pasando por el desinterés por cualquier realidad que no sea la persona amada. Es un síntoma de vivir completamente para esa persona el:

«que no pueda el amante dirigir la palabra a otra persona que no sea su amado, aunque se lo proponga, pues entonces la violencia quedará patente para quien lo observe; que calle embebecido, cuando hable el amado". ${ }^{56}$

Ibn Hazm muestra muchas señales del fervor y la adoración que se dirigen quienes están enamorados. Algunos ejemplos entre miles son:

«el forcejear por cualquier cosa que hayan cogido uno de los dos» $»^{57}$, «hacerse frecuentes guiños furtivos ${ }^{58}$, «el cogerse intencionadamente las manos mientras hablan $»^{59}$, «el acariciarse los miembros visibles, done sea hacedero ${ }^{60}$, «El beber lo que quedó en el vaso del amado, escogiendo el lugar mismo donde posó sus labios» ${ }^{61}$.

La razón de esta adoración y devoción por el otro implica que el otro ha dejado de ser cualquier otro. Es un ser que pasa a ser necesario, tan

[53] Ibid., pp. 138

[54] Ibn Hazm, op. cit., p. 170.

[55] Ibidem.

[56] Ibid., pp. 138 - 139

[57] Ibid., p. 141

[58] Ibidem

[59] Ibidem

[60] Ibidem

[61] Ibidem 
necesario como la propia vida, el propio origen, o el mismísimo Dios. Eso es lo que explica:

«Que el amante vuele presuroso hacia el sitio en que está el amado; que busque pretextos para sentarse a su lado y acercarse a él: y que abandone los trabajos que le obligarían a estar lejos de él.. ${ }^{62}$

Este vivir en el amado, y descubrir su necesidad respecto de la propia vida, implica también el descubrimiento de una necesidad en el propio vivir del amante. Se descubre un sentido para el vivir, y una felicidad que, aún siendo contingente en su causa, es a la que uno le parece estar destinado necesariamente.

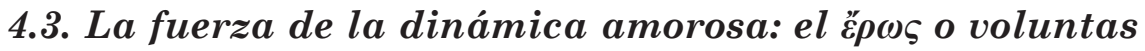 ut natura
}

Cuando Ibn Hazm comienza a tratar de la esencia del amor en el capítulo I de nuestra obra, discute el platonismo de Ibn Dāwūd, otro zahirita como él.

\begin{abstract}
«Difieren entre sí las gentes sobre la naturaleza del amor y hablan y no acaban sobre ella. Mi parecer es que consiste en la unión entre partes de almas que, en este mundo creado, andan divididas, en relación a como primero eran en su elevada esencia; pero no en el sentido en que lo afirma Muhammad ibn Dāwūd (¡Dios se apiade de él!) cuando, respaldándose en la opinión de cierto filósofo, dice que "son las almas esferas partidas", sino en el sentido de la mutua relación que sus potencias tuvieron en la morada de su altísimo mundo y de la vecindad que ahora tienen en la forma de su actual composición. $»^{63}$
\end{abstract}

Ibn Hazm piensa que la naturaleza del amor es unitiva. Pero no unitiva de los individuos enteros, sino de ciertas partes de sus almas. Por eso se opone a la posición de Aristófanes en El banquete platónico que sostenía su antecesor Ibn Dāwūd. Aristófanes había señalado que cada uno de nosotros era la mitad de un ser originario. Y que, tras un castigo divino, y nuestra caída en la existencia en el mundo sensible, buscaba ansiosamente la unidad con la otra mitad de sí.

A diferencia de Ibn Dāwūd la naturaleza unitiva del amor, en la que radica su fuerza, no es por la incompletitud del propio ser, ${ }^{64}$ sino por la

[62] Ibidem

[63] Ibn Hazm, El collar de la paloma..., p. 128.

[64] Para Miguel Cruz Hernández también resulta evidente que no se puede reducir el platonismo de Ibn Hazm al de Ibn Dāwūd: «En las doctrinas del amor a la belleza, que no sólo aparecen en el Collar de la Paloma, sino también en Los caracteres y la conducta, la influencia neoplatónica es bien evidente ; y aunque ésta haya querido centralizarse a través de la influencia de Muhammad lbn Dāwūd, cuyo Kitab al-Zahra parece manejar, este influjo, para algunos decisivo, hay que reducirlo a la vista de las muchas doctrinas neoplató- 
«mutua relación que sus potencias tuvieron», es decir, por la afinidad de sus intelectos, de sus voluntades, de su afectividad, etc. Esta mutua relación es situada por Ibn Hazm en un pasado inmemorial. En este sentido está fuera de la elección y de la autodeterminación, es decir de la libertad. Por eso, el alma al presentir esta mutua relación tiende espontánea y sentimentalmente a amar (sin poder elegir), como a su felicidad.

Pero no sólo eso, Ibn Hazm añade que sin el conocimiento y el trato en este mundo sensible — «la vecindad que ahora tienen»—, no sería posible la unión amorosa. Y esto implica que aquel acto de amor, cuyo centro no radicaba en la elección, es confirmado libremente.

No obstante, este mutuo conocimiento, y estas afinidades en la forma de pensar, de querer, de sentir, etcétera, en las que radica la esencia del amor son del alma. Por eso, en el texto citado habla de «la forma de su actual composición». Se trata de la composición alma-cuerpo. La fuerza del amor arranca del alma, de unas afinidades primigenias, y no del cuerpo. Esta es la razón por la que se ha acusado a Ibn Hazm de una defensa exclusiva del amor udrí a cortés.

Más que amor cortés, lo que hay es un platonismo muy puro. No en la línea que sostiene Aristófanes en El simposium, o ibn Dāwūd en su obra poética, sino en la que defienden Diotima y Sócrates en ese mismo diálo-

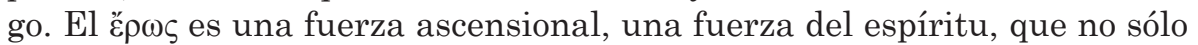
busca a la otra mitad en este mundo, sino la elevación de sí mismo - mediante la creación, mediante la realización de la esencia del otro- . No se trata de buscar en la otra persona a uno mismo. A eso se restringe el ideal amatorio de Aristófanes. Esto es egoísmo craso, o narcisismo. Se trata de buscar la elevación de la otra persona mediante las propias acciones. En este crear o producir o promover el bien del otro, y sólo de ese modo, uno se eleva también..$^{65} \mathrm{Y}$ esto significa ser sí mismo por mediación del otro. Pero como es un amor que despierta a la relación que los dos seres tuvieron, la unificación con la persona amada es exigencia de unidad e identidad, y no de dispersión.

nicas sicológicas y metafísicas que aparecen en los escritos de lbn Hazm y que nose encuentran en el Kitab al-Zahra de Muhammad lbn Dāwūd.»

[65] Me parece que la determinación del amor por parte de Ibn Hazm coincide con la que realiza uno de los mayores estudiosos actuales sobre el amor. Me refiero al profesor Tomás Melendo. Éste siguiendo a Aristóteles define el amor como el querer el bien para el otro en cuanto otro. Cfr.: Melendo, T., Ocho lecciones sobre el amor humano, Rialp, Madrid, 2002 (4ª edición). La lección primera versa que trata igual que el capítulo primero de El collar de la paloma «sobre la esencia del amor» se divide en tres epígrafes: corroborar en el ser, deseos de plenitud y entrega. Me parece que Melendo coincide en términos generales con Ibn Hazm. El alma es afín en alguna potencia espiritual al ser de otra persona. Se inflama en deseos de plenitud al corroborarla, es decir, al desear su plenitud. Este deseo se vierte naturalmente en la entrega al ser amado. 
Es preciso insistir en el texto citado de Ibn Hazm. Allí se habla de «la unión entre partes de almas que, en este mundo creado, andan divididas, en relación a como primero eran en su elevada esencia [...] en el sentido de la mutua relación que sus potencias tuvieron en la morada de su altísimo mundo». ${ }^{66}$ Según esto, este mutuo creado es para las almas un

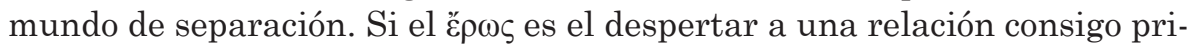
migenia, entonces el alma cuando se enamora toma conciencia de sí misma de un modo muy determinado y muy radical. Aparece, por medio de otra persona, aquello en lo que consiste ser sí mismo de modo máximo. El ser humano entonces, y sólo entonces, alcanza a afirmar su propia identidad, al presentir cómo estaban dispuestas sus potencias en su anterior morada. Uno adquiere un presentimiento de lo que uno realmente es, que afirma y que quiere mediante la experiencia de la alteridad amada.

Ya Ortega resalta en su «Prólogo» al Collar de la paloma el poder elevador, ascendente, que tiene el amor:

«El Eterno-femenino es una realidad peraltada, a la cual el hombre, cuando ama, se eleva, no por propio poder ascensional, sino porque es atraído -atraido hacia lo más alto-». ${ }^{67}$

Ortega está citando a Goethe cuando dice que «el eterno femenino nos atrae hacia lo alto». El Eterno-femenino — das Ewig-Weibliche ${ }^{68}$ _ es el tipo o concepto ideal de mujer. Se trata de un ideal inmutable, es decir ahistórico, en el que se condesaría la esencia de lo femenino. Es un arquetipo, como una idea platónica, una esencia, de lo femenino, sumamente idealizada o romántica. La mujer aparece ahí, no como lo mundano, lo sensual, sino cuasi angelical. No como lo activo, que es lo Eterno-masculino, sino como lo contemplativo. Nietzsche, que criticará el modelo de los dos sexos en la Alemania del siglo XIX, caracteriza más aún lo Eterno-femenino. Para él las virtudes femeninas serían privadas; las masculinas en cambio, públicas. Estas virtudes serían las del cuidado - a los que llegan al mundo y a los que parten de él-, las del servicio, las de la guarda de la moral, y las del poder de redimir. ${ }^{69}$

Pues bien, creo que Ibn Hazm se aparta del ideal del Eterno-femenino. Para que se encienda la llama del amor, basta con la afinidad espiritual, con la afinidad en las potencias anímicas. No se trata tanto de amar

[66] Ibn Hazm, El collar de la paloma..., p. 128.

[67] Ortega, J. «Prólogo» en Op. cit., p. 12.

[68] Goethe, Fausto, Abada, Madrid, 2010, Parte II, p. 792.

[69] Nesbitt Oppel, F., Nietzsche On Gender: Beyond Man And Woman, University of Virginia Press, 2005, pp. 4-7 
un arquetipo, sino de amar una cualidad espiritual con la que uno es afín, y en la que se refleja la propia radicalidad.

\begin{abstract}
«el secreto de la atracción o del desvío entre las cosas creadas está en la afinidad o repulsión que hay entre ellas, porque cada cosa busca siempre a su semejante, lo afín sólo en su afín sosiega, y esta comunidad de especie ejerce una acción que los sentidos perciben y una influencia que salta a la vista. La mutua antipatía entre los contrarios, la mutua simpatía entre los iguales, el ímpetu que enlaza a las cosas parejas entre sí.» ${ }^{70}$
\end{abstract}

Ibn Hazm está tratando aquí justamente de la fuerza del amor. Según él es algo que ha pasado con frecuencia desapercibido. Habla de un secreto. La atracción tiene su origen en la afinidad espiritual. Pero aquí vemos la agudeza psicológica de Ibn Hazm. En efecto, él señala que esta afinidad en lo espiritual es algo perceptible. Aunque sea una afinidad espiritual, el mutuo gusto o la mutua antipatía es revelador del amor, de esa afinidad en lo espiritual. Parece que nos gusta lo sensible de otra persona, pero este gusto o disgusto apuntan a nuestra compatibilidad espiritual, y no meramente corporal.

La prueba de esto la da Ibn Hazm al señalar que:

«a menudo vemos que hay quien prefiere alguien de inferior belleza con respecto a otros cuya superioridad reconoce, y que, sin embargo, no puede apartar de él su corazón.» ${ }^{71}$

Así pues, el amor es algo psíquico, que afecta al alma y que uno reconoce por el gusto sensible en el alma del otro, y que cuando es captado por el ser humano enciende en él una fuerza - a la que Platón en El ban-

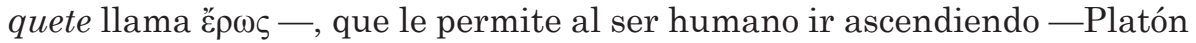
llegará a decir, que le salen alas- hasta el mundo de las ideas, de lo eterno, saliendo de esta caverna en la que los seres humanos han caído.

Antes dijimos que resultaba imposible reducir a unidad las causas del amor, y concluíamos que era algo gratuito, y que no cabía ciencia alguna sobre su génesis. Dicho en terminología metafísica, el origen de la dinámica amorosa es algo per accidens; pero si nos elevamos del plano existencial al metafísico, entonces podríamos decir que per se, el amor parece que encuentra siempre su origen en la captación de una afinidad espiritual. Por eso tengo que criticar la opinión de López Pita cuando dice que «es evidente que el alma es bella y, por tanto, suspira por todo lo hermoso, y siente inclinación por las imágenes perfectas; y si luego distingue tras esa imagen alguna cosa que le sea afín, se une con ella y nace el verdadero

[70] Ibn Hazm, El collar de la paloma..., op. cit., p. 128.

[71] Ibid., p. 129. 
amor». ${ }^{72}$ Pita no acierta a comprender la opinión de Ibn Hazm. No es toda realidad hermosa la que provoca irresistiblemente el amor, sino aquella realidad con la que se es afín espiritualmente, es decir en alguna potencia del alma. La opinión de López Pita es más una confesión de platonismo que de comprensión de la filosofía de Ibn Hazm.

\subsection{La elección amorosa: culminación del dinamismo eró- tico}

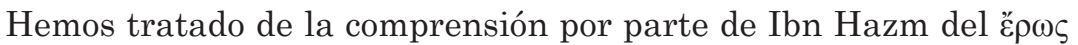
platónico. Hemos visto que es una fuerza que enciende y eleva al alma espontáneamente, llevándola a amar pre-reflexiva o espontáneamente la radicalidad de su sí mismo que comparece gracias a la alteridad de la persona amada. Esta identidad radical del sí mismo que el hombre descubre merced a la persona amada es el requisito para poder tomar posesión de sí mismo. Esta toma de posesión sólo puede darse y entregarse a la persona amada en función de una decisión, la decisión de la entrega. Y con esto llegamos al tema de la voluntad electiva, que los filósofos medievales denominaron voluntas ut ratio.

Ibn Hazm parte del estado actual del alma enamorada. Es decir de una vida que se desarrolla en el tiempo, y que es finita.

«El alma está, en este mundo inferior, tapada por velos físicos, envuelta en accidentes, y ceñida
por inclinaciones terrenales y mundanas, que encubren buena parte de sus cualidades y que, aun
cuando no alteren su esencia, se interponen a lo menos entre ella y las demás almas. La unión ver-
dadera no puede, por tanto, conseguirse sino luego que el alma está presta y dispuesta para ella; una
vez que le ha llegado el conocimiento de aquello que se le asemeja y con ella coincide; después de
haber contrastado sus propias cualidades naturales, ocultas en ella, con aquellas del amado que se le
parecen. Sólo entonces se producirá la unión verdadera con el amado, sin impedimento alguno.»

La plenitud a la que aspira el alma en esta vida, la identidad que ha vislumbrado el enamorado, ha de realizarse por medio de la relación amorosa. Pero esta unidad con "su esencia» puede no realizarse. Entonces, en lugar de unidad, lo que habrá es dispersión, pérdida de uno mismo. Como hemos visto, la relación amorosa despierta al alma a su esencia, le permite ver su identidad a pesar de estar «tapada por velos físicos, envuelta en accidentes y ceñida por inclinaciones [...] que encubren buena parte de sus cualidades». Este es el primer momento, el del encenderse del amor. Pero que la paloma alce el vuelo, que se logre la unión consigo por medio

[72] López Pita, P. Op. cit., p. 78.

[73] Ibn Hazm, El collar de la paloma.., p. 164. 
de la persona amada, sólo es posible desde una voluntad reflexiva. El alma ha de estar "presta y dispuesta».

El amor no es un mero sentimiento para Ibn Hazm, y no lo es porque el sentimiento es tornadizo, voluble.

\begin{abstract}
«Lo que suele ocurrir en un primer momento son algunos accidentes de atracción corporal y de aprobación visual, que no van más allá de las apariencias físicas, y éste es el secreto del apetito carnal, tomado en su verdadero sentido; el cual apetito toma tan sólo nombre de amor cuando se supera a sí mismo y traspasa esto límites, siempre que su rebasamiento coincida con una unión espiritual en que tengan parte el alma y sus cualidades naturales.» ${ }^{74}$
\end{abstract}

El amor no es algo tan accidental como un afecto corporal. Eso sería depender de los accidentes de la vida. Pero con ellos el ser humano se dispersaría, no lograría afirmar la identidad descubierta por medio de la persona amada. Afirmar esta identidad, no dispersarse, exige un acto electivo y reflexivo de amor. Si no, el encenderse del ह̌

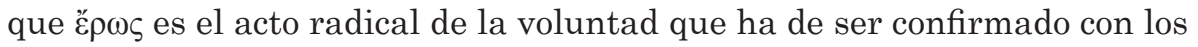
propios actos durante el transcurso de la vida con los actos reflexivos de una voluntad que afirma lo amado.

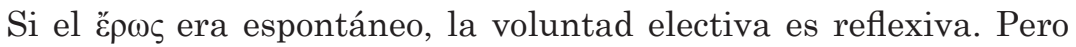
una elección reflexiva —-deliberada- que continúa lo vislumbrado en el momento de iluminación de la voluntad y del propio ser. «No diría yo que era esto artificio, sino natural verdadero y fruto de un no forzado albedrío». ${ }^{75} \mathrm{Si}$ el है $\rho \omega \varsigma$ se refiere al fin, la voluntad electiva se refiere a los medios necesarios a lo largo del despliegue existencial para querer y seguir queriendo.

«Cuando deseamos una cosa, fuerza es que busquemos un medio que nos conduzca a ella o un camino que hacia ella nos lleve, pues el único que puede crear cuanto le apetezca sin necesidad de medianeros es el Sabio Primero (¡ensalzada sea su alabanza!).» ${ }^{76}$

Sólo con esta búsqueda de los medios es posible poner la radicalidad de uno mismo en manos de las decisiones propias. Eso es el compromiso con lo vislumbrado en el momento inicial del amor.

\title{
5. Breve conclusión
}

Mi intención en este trabajo ha consistido en ofrecer y corroborar una hipótesis interpretativa del tratamiento de la dinámica de las relaciones amorosas en El collar de la paloma. Con frecuencia esta obra es

[74] Ibidem.

[75] Ibid., p. 168.

[76] Ibid., p. 172. 
interpretada desde categorías como las del amor erótico y/o el amor cortés. Mi hipótesis consiste en mostrar que Ibn Hazm articula de modo admirable las dimensiones amorosas de la espontaneidad y la elección, o lo que es lo mismo, uno podría rastrear en su pensamiento la articulación entre lo que otros filósofos medievales ulteriores llamarán voluntas ut natura y voluntas ut ratio. Me parece que este marco permite entender la etiología, la fuerza de la dinámica amorosa y su culminación en el tema de la elección amorosa. 
